\title{
ANÁLISE SÓCIO TEMPORAL DO MUNICÍPIO DE BRASILÂNDIA, MATO GROSSO DO SUL.
}

\author{
Camila Balista Garbeline ${ }^{1}$
}

\section{RESUMO}

A análise sócio temporal do município de Brasilândia tem como objetivo analisar os aspectos físicos da área, mostrar o uso e ocupação do solo e fornecer informações metodológicas aplicadas. Das técnicas usadas de Sensoriamento Remoto e Geoprocessamento foi possível confeccionar mapas de uso e ocupação dos anos de 1999 e 2011, para mostrar as mudanças no ambiente no decorrer dos anos. Podendo por meio desse estudo propor medidas para a recuperação da área e prevenção de futuros impactos ambientais. O município de Brasilândia está entre as coordenadas de Longitude $53^{\circ}$ $08^{\prime} 5^{\prime \prime}$ a $51^{\circ} 50^{\prime} 44^{\prime \prime}$ W e Latitude $21^{\circ} 12^{\prime} 47^{\prime \prime}$ e $20^{\circ} 40^{\prime} 57^{\prime \prime} \mathrm{S}$ (IBGE, 2015).

PALAVRAS-CHAVE: Bacia hidrográfica, sensoriamento remoto, uso do solo.

\section{ANALYSIS PARTNER THUNDERSTORM BRASILÂNDIA COUNTY , MATO GROSSO DO SUL.}

\begin{abstract}
The temporal analysis of socio Brasilândia municipality aims to analyze the physical aspects of the area show the use and occupation of land and provide methodological information applied. The technique of Remote Sensing and GIS was possible to make use of maps and occupation of the years 1999 and 2011, to show the changes in the environment over the years. Can through this study propose measures for the recovery of the area and prevent future environmental impacts. The municipality of Brasilândia is among the coordinates Longitude $53^{\circ} 08$ ' 5 ' 'to $51^{\circ} 50^{\prime} 44$ " W and Latitude $21^{\circ} 12$ ' $47^{\prime}$ 'and $20^{\circ} 40^{\prime} 57^{\prime \prime} \mathrm{S}$ (IBGE, 2015).
\end{abstract}

KEYWORDS: River basins, remote sensing, land use.

\section{ANÁLISIS SOCIO TRONADA BRASILÂNDIA CONDADO, MATO GROSSO DO SUL .}

\footnotetext{
${ }^{1}$ Graduação e Mestrado em Geografia, Professora na Universidade Federal de Mato Grosso (UFMT). E-mail: camila.garbel@gmail.com
} 


\section{RESUMEN}

El análisis temporal del municipio socio Brasilândia tiene como objetivo analizar los aspectos físicos de la zona muestran el uso y ocupación de la tierra y proporcionan información metodológica aplicada. Las técnicas de Teledetección y SIG fue posible hacer uso de mapas y ocupación de los años 1999 y 2011, para mostrar los cambios en el medio ambiente en los últimos años. Puede través de este estudio proponer medidas para la recuperación de la zona y prevenir futuros impactos ambientales. El municipio de Brasilândia está entre las coordenadas Longitud $53^{\circ} 08$ ' 5 ' 'a $51^{\circ} 50^{\prime} 44$ " W y latitud $21^{\circ} 12^{\prime} 47^{\prime}$ 'y $20^{\circ} 40^{\prime} 57$ " S (IBGE, 2015).

PALABRAS CLAVE: cuencas de los ríos, de teledetección, uso de la tierra.

\section{INTRODUÇÃO}

O ambiente pode ser afetado e descrito por aspectos físicos, químicos, biológicos e antrópicos. Desta forma, quando se trata do construído pelo homem a degradação pode ter uma maior ou menor intensidade, dependendo das técnicas utilizadas na exploração, e com a preocupação com a conservação dos recursos naturais (GUERRA e CUNHA, 2007).

Para Lepsch (2002) parece que o homem se empenha em acelerar o empobrecimento do ambiente: as matas são derrubadas e queimadas desordenadamente, os pastos são superlotados com rebanhos, as encostas íngremes são aradas na direção da maior declividade, as terras são submetidas à monocultura, ao longo do tempo, sem proteção contra o arraste pelas enxurradas ou devolução da fertilidade com adubos.

Devido ao aumento das degradações, fez surgir à preocupação com os impactos ambientais, sendo essas mudanças ocorridas e somadas ao longo da história até chegar num patamar de preocupação com as questões ambientais.

Sabe-se que os corpos d'água sofrem todo tipo de danos, resultado da exploração e ocupação humana em certas áreas. Sendo alterado na maioria das vezes através do incorreto uso da terra, podendo ocorrer processos erosivos, dificultando a recuperação da área (GUERRA e CUNHA, 2007). É nesse contexto que se inseri a bacia hidrográfica, pois é uma unidade de interação dos setores sociais e naturais, deve a essa interação ser administrada para minimizar os impactos ambientais.

Dessas preocupações surgi o conceito de planejamento voltado para a conservação ambiental. E para um planejamento adequado deve-se buscar antecipar as necessidades para as futuras gerações de maneira a garantir o 
equilíbrio do meio ambiente. Por isso é importante conhecer o espaço, tempo (processo de transformação), sociedade e a natureza, assim podendo elaborar diagnósticos e estabelecer diretrizes para diminuir os efeitos negativos no ambiente.

Nesse sentido Floriano (2004, p.08) comenta:

[...] processo de organização do trabalho de uma equipe para consecução de objetivos comuns, de forma que os impactos resultantes que afetam negativamente o ambiente em que vivemos sejam minimizados e que os impactos positivos sejam maximizados.

Com um planejamento ambiental se tem a possibilidade de recuperar e analisar possíveis áreas degradadas. Por meio do estudo de uso e ocupação do solo das unidades das paisagens, podem-se elaborar diagnósticos quando é percebido o uso inapropriado dos recursos naturais.

Para a realização do trabalho foram usadas imagens de satélite, a qual se tornam ferramentas imprescindíveis para a análise sócio temporal da área, desta forma foi possível comparar os dados e mostrar as mudanças que ocorreram no ambiente no passar dos anos.

O trabalho tem como objetivo realizar uma análise sócio temporal, diagnosticar as características físicas, econômicas e ambientais, levando em consideração as fragilidades e as alterações que ocorreram em virtude da ocupação desordenada do território.

O município de Brasilândia se localiza na região leste do Estado de Mato Grosso do Sul, região Centro-Sul do Brasil. Faz limite com os municípios de Três Lagoas, Água Clara, Ribas do Rio Pardo e Santa Rita do Pardo, está entre as coordenadas de Longitude $53^{\circ} 08^{\prime} 5^{\prime \prime}$ a $51^{\circ} 50^{\prime} 44^{\prime \prime}$ W e Latitude $21^{\circ} 12^{\prime} 47^{\prime \prime}$ e $20^{\circ}$ 40' 57' S (IBGE, 2015) (Figura 1). 
Figura 1: Carta base de localização do município Brasilândia - MS

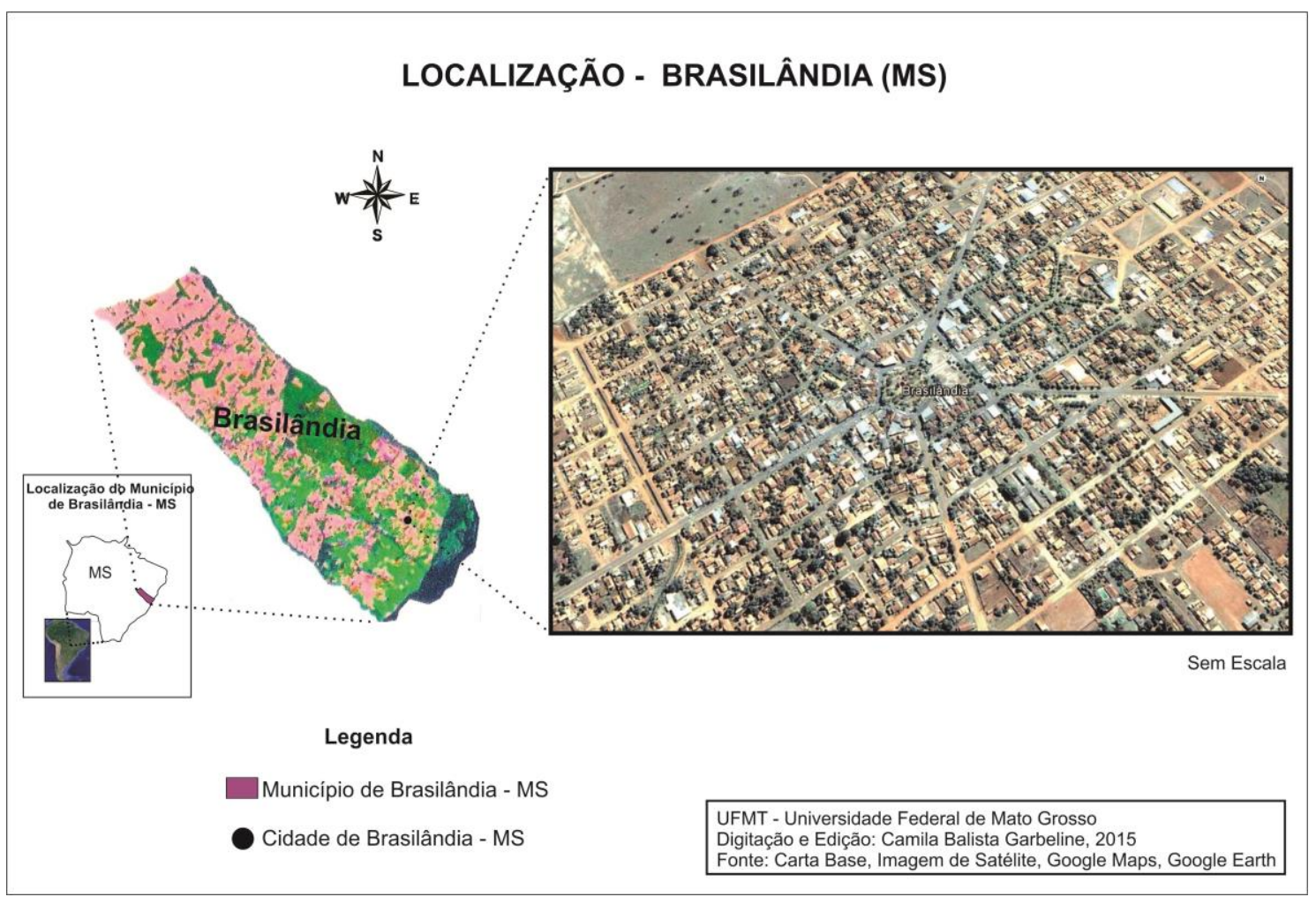

Edição: Camila Balista Garbeline, 2015

\section{METODOLOGIA}

Para o desenvolvimento do trabalho foram utilizados materiais cartográficos, SIG, sensoriamento remoto e softwares para o processamento e análise das imagens da área do estudo.

A caracterização das imagens e das classes de uso foi realizada com as imagens de satélite LANDSAT TM +5 referentes a 1999 e 2011. As imagens foram escolhidas com intervalos de tempo longo devido à resolução espacial. A imagem de 1999 foi escolhida por pensar em uma data com mais de 10 anos de intervalo da imagem de 2011, a imagem com melhor visualização encontrada foi do dia 02/05/1999. Sobre a escolha da imagem referente ao ano de 2011 e não do ano atual foi devido à disponibilidade da imagem, e ao percentual de nuvens.

As imagens de satélite foram gravadas no formato TIFF e expostas para o formato GRIB no SIG (Sistema de Informação Geográfica), Spring, software elaborado pelo INPE (Instituto de Pesquisas Espaciais). 
Essas imagens foram importadas e georreferenciadas por meio de pontos de controles passíveis de identificação na imagem e na carta topográfica. Após o georreferenciamento das imagens, o contraste foi executado, a fim de melhorar a qualidade da imagem. A partir da composição colorida feita com o contraste, possibilitou a classificação do uso e ocupação do solo na bacia.

A classificação foi supervisionada por atributos das regiões, utilizando 0 classificador Bhattacharya do Spring, cujo limiar de aceitação é de 99,9\%.

Após a classificação, foi aplicado o mapeamento de classes, o qual possibilitou quantificar o uso e ocupação do solo em cada classe, são elas: área urbana, cana de açúcar, corpos d'água, pastagem, silvicultura, solo exposto, vegetação natural, vegetação rasteira e vegetação úmida.

O estabelecimento de classes é uma técnica que facilita a distinção da evolução e transformação da paisagem com o passar dos anos numa determinada área.

Durante o estudo a imagem foi interpretada com os elementos - forma, tonalidade, cor e textura, juntamente com as imagens do Google Earth.

Ao final foi possível alcançar uma tubulação cruzada das duas imagens trabalhadas, com as imagens temáticas selecionadas, com o Pl ativo e $\circ \mathrm{PI}$ de interseção digitados, possibilitou em seguida executar e obter os dados do cruzamento das cenas.

\section{RESULTADOS}

Os produtos gerados através da utilização do SIG possibilitou comparar as imagens pelo uso e ocupação do solo (Figura 2). Por fim quantificar separadamente as classes em $\mathrm{km}^{2}$, e uma porcentagem de cada classe para os anos de $1999 \mathrm{e}$ 2011 (Tabela 1). 
Figura 2: Uso e ocupação do solo no município de Brasilândia (MS), ano 1999 e 2011

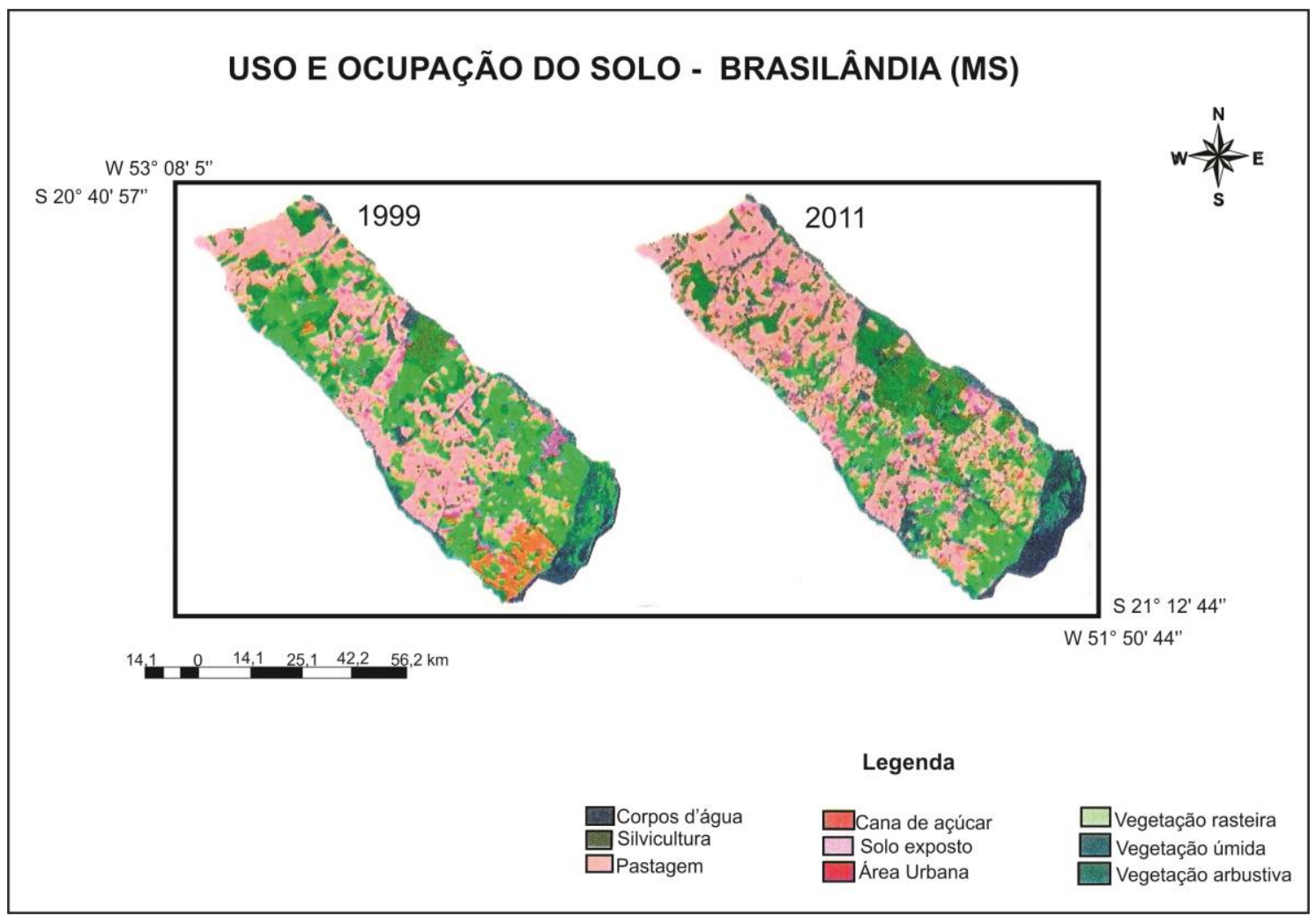

Fonte: Imagens de Satélite e Spring

Edição: Camila Balista Garbeline, 2015

Tabela 1: Classificação de uso e ocupação do solo no município de Brasilândia (MS) - 1999 e 2011

\begin{tabular}{|c|c|c|}
\hline $\begin{array}{l}\text { Município de Brasilândia } \\
\text { Classes de uso do solo }\end{array}$ & $\begin{array}{c}\text { Área }-\mathbf{k m}^{2} \\
\text { Ano } 1999\end{array}$ & $\begin{array}{l}\text { Área }-\mathbf{k m}^{2} \\
\text { Ano } 2011\end{array}$ \\
\hline Área Urbana & 3,32 & 5,06 \\
\hline Cana de açúcar & 255,94 & 100,20 \\
\hline Corpos d'água & 96,88 & 296,77 \\
\hline Pastagem & 2340,55 & 2745,62 \\
\hline Silvicultura & 127,45 & 331,99 \\
\hline Solo Exposto & 214,91 & 169,74 \\
\hline Vegetação Natural & 768,95 & 723,38 \\
\hline Vegetação Rasteira & 1513,87 & 804,37 \\
\hline Vegetação Úmida & 512,45 & 657,19 \\
\hline Total & 5834,32 & 5834,32 \\
\hline
\end{tabular}

Organização: Camila Balista Garbeline, 2015

Observa-se que os corpos d'água no transcorrer dos anos estudados apresentaram um crescimento, em 1999 estava com 1,66\%, passando para 5,08\% da área em 2011. Esse crescimento está relacionado de acordo com Oliveira (2002) 
com a construção da Usina Hidrelétrica Porto Primavera, um dos municípios que sofreu influência foi o de Brasilândia (MS), inundando com o desvio do rio 49.531 hectares do município. A primeira fase do desvio do rio aconteceu em 1980, e o prazo previsto para a primeira fase de inundação era de 43 meses, a segunda fase de 15 meses e finalmente para e enchimento 3 meses.

A vegetação arbustiva com o passar dos anos apresentou um decréscimo, em 1999 estava com 13,17\% e passou para 12, 39\% em 2011. Essa diminuição pode ser devido à área desmatada.

A vegetação rasteira apresentou uma diminuição, em 1999 estava ocupando uma área de 25,94\%, e no ano de 2011 passou a ocupar $13,78 \%$.

A vegetação úmida também apresentou um crescimento, passando de $8,78 \%$ para 11,26\% nos anos de 1999 e 2011 respectivamente. Esse crescimento pode ser influência do aumento dos corpos d'água, e a preservação das áreas ao redor do córrego.

Pastagem mostrou ser predominante na área, em 1999 apresentou 40,11\% de toda a área da bacia, e em 2011 ocupou 47,05\%, demonstrando também que continua crescendo como atividade econômica.

A silvicultura apresentou um crescimento no decorre dos anos, em 1999 apresentou 2,18\% e em 2011 aumentou para 5,69\%. Mostrando que essa atividade também está crescendo no município.

A cana de açúcar apresentou uma diminuição nos dois anos estudados, em 1999 estava com 4,38\% e em 2011 passou para 1,71\%.

Nesta área como demonstra os dados, há pouca ocupação antrópica, em 1999 estava ocupando 0,05\% da área, e em 2011 passou para 0,08\% de área urbana.

A classe de solo exposto, que são áreas de resultado do pisoteio do gado, áreas muito degradadas que não tem um fim econômico de uso. Ou um solo sendo trabalhado, sendo exposto para algum tipo de plantio. Em 1999 essa classe representava $3,68 \%$ diminuindo em 2011 para $2,90 \%$. 
Figura 3- Falta de manejo na estrada (A), degradação ambiental (B) e solo exposto para plantio (C).

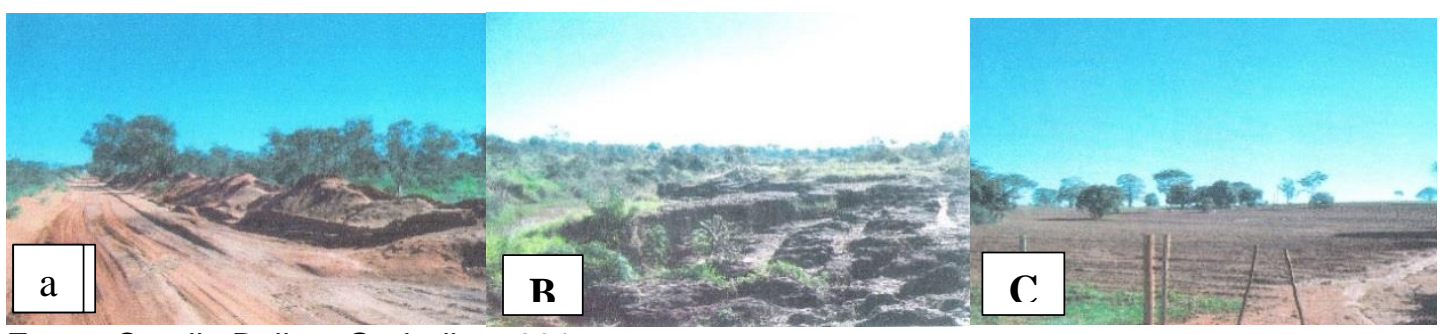

Fonte: Camila Balista Garbeline, 2015

Percebe-se na figura 3 solos expostos, sabe-se que sem um manejo adequado o solo fica frágil e sem nutrientes, podendo ter ravinamento em períodos de tempo curto, um escoamento superficial da água, entre outros problemas.

Segundo Crepani (2001) o tempo de formação dos solos é bem variável, podem demorar centenas a milhares de anos para formar $1 \mathrm{~cm}$, mas com um manejo inadequado pode-se perder em apenas dias, por isso práticas conservacionistas e sistemas de manejo adequado para cada tipo de solo são essenciais.

O uso e ocupação do solo de cada sub - bacia do município de Brasilândia (MS) para atividades econômicas no decorrer dos anos 1999 e 2011 é demonstrado e comparado a seguir (Tabela 2).

Tabela 2: Análise por atividade econômica

\begin{tabular}{lcccccc}
\hline \multicolumn{7}{c}{ Análise do Uso e Ocupação do Solo por Atividade Econômica } \\
\hline Sub - Bacias & Ocupação & \multicolumn{7}{c}{ Pasto (\%) } & Silvicultura (\%) & Cana de açúcar (\%) \\
Anos & $\mathbf{1 9 9 9}$ & $\mathbf{2 0 1 1}$ & $\mathbf{1 9 9 9}$ & $\mathbf{2 0 1 1}$ & $\mathbf{1 9 9 9}$ & $\mathbf{2 0 1 1}$ \\
Córrego Barreirinho & 52,13 & 66,51 & 00 & 1,40 & 0,24 & 0,25 \\
Córrego Barreiro & 36,44 & 52,30 & 11,68 & 0,13 & 0,36 & 1,15 \\
Córrego Beleza & 23,14 & 20,77 & 00 & 00 & 0,28 & 0,15 \\
Córrego Bom Jardim & 41,82 & 58,51 & 0,02 & 2,29 & 1,50 & 3,07 \\
Córrego Cabaça & 40,39 & 3,64 & 00 & 58,89 & 0,05 & 0,75 \\
Córrego Cachoeirinha & 75,18 & 78,40 & 00 & 00 & 0,20 & 0,20 \\
Córrego Canivete & 49,42 & 45,39 & 00 & 0,04 & 0,09 & 3,48 \\
Córrego Formoso & 21,2 & 55,59 & 00 & 7,79 & 1,38 & 3,51 \\
Córrego Jatobá & 65,60 & 32,46 & 00 & 0,19 & 0,79 & 0,46 \\
Córrego Paredão & 23,83 & 42,13 & 00 & 0,18 & 25,59 & 6,71 \\
Córrego Pedra Bonita & 30,46 & 59,22 & 0,16 & 00 & 3,62 & 0,74 \\
Córrego Piruá & 57,17 & 51,69 & 00 & 0,09 & 1,40 & 3,67 \\
\hline
\end{tabular}




Córrego Sapé
Ribeirão Água Limpa
Ribeirão Boa Esperança
Ribeirão Geriva
Ribeirão Invejoso
Ribeirão do Meio
Ribeirão Pelado
Ribeirão Serrote

$\begin{array}{ccc}22,24 & 28,30 & 13,80 \\ 54,9 & 67,36 & 00 \\ 40,66 & 39,24 & 0,03 \\ 60,55 & 32,11 & 00 \\ 65,67 & 53,12 & 0,57 \\ 46,86 & 58,82 & 00 \\ 77,68 & 53,82 & 00 \\ 20,60 & 64,02 & 00\end{array}$

20,67
0,02
5,66
19,88
0,12
0,08
1,02
00

1,61

0,82

Organização: Camila Balista Garbeline, 2015

O quadro nos mostra que a maioria das sub - bacias estão ocupadas por pastos, percebe-se que sempre foi predominante essa atividade, e continua em expansão como atividade econômica.

A atividade que também apresenta um crescimento é a silvicultura. Entre todas as sub - bacias, as que mais predominam essa atividade econômica são as sub-bacias Córrego Sapé e Córrego Cabaça.

A cana de açúcar mostrou crescimento no ano de 2011 como atividade econômica nas sub - bacias Ribeirão do Meio, Ribeirão Geriva e no Córrego Canivete, porém com menor expressão se comparada com o pasto e a silvicultura.

\section{CONCLUSÃO}

Os mapas são de grande importância para obtenção e análise ambiental. Os resultados adquiridos nas imagens de satélite através do emprego Spring (SIG), nos permitiu interpretar e relacionar os dados, demonstrando as mudanças ocorridas no ambiente.

Analisando o uso e ocupação do solo nos anos de 1999 e 2011, conclui-se que as classes de pasto e silvicultura estão crescendo como atividade econômica na região. Já a cana de açúcar com o passar dos anos conclui-se que essa classe vem diminuindo, sendo ocupada em sua maior parte pela vegetação rasteira.

Portanto percebe-se que a maior parte do uso do solo do município de Brasilândia (MS) é para pastagem, e vem sendo desenvolvidas culturas. A partir desses resultados sugerem-se para não degradar o ambiente, que se utilizem sistemas de manejo como curva de nível, técnicas de conservação do solo, árvores 
reflorestadas, evitando assim o escoamento superficial da água, demorando mais tempo para ter ravinamento, empobrecimento do solo, entre outros problemas.

Não houve um planejamento da ocupação por parte desse estudo, mas em algumas áreas já degradadas como demonstrados, é essencial um planejamento adequado, com o desenvolvimento de diagnósticos ambientais em coordenação com os estudos técnicos, assim levando o ambiente degradado a uma condição ambiental melhor do que a situação atual, podendo explorar oportunidades benéficas, evitando afeitos desastrosos.

\section{BIBLIOGRAFIA}

AMEIDA, J. R. de; BASTOS, A. C. S.; MALHEIROS, T. M.; SILVA, D.M. Política e Planejamento. Rio de Janeiro: Thex Editora, 2008.

CREPANI, E. Sensoriamento Remoto e Geoprocessamento Aplicados ao Zoneamento Ecológico Econômico e ao Ordenamento Territorial. INPE, São José dos Campos, SP, 2001.

FLORIANO, E. P. Planejamento Ambiental. Rio Grande do Sul: Santa Rosa, 2004.

GUERRA, A. J. T.; CINHA, S. B. (Org). Geomorfologia e Meio Ambiente. Rio de Janeiro: Bertrand Brasil, 2007.

INSTITUTO BRASILEIRO DE GEOGRAFIA E ESTATÍSTICA. IBGE, Cidades. Disponível em: $<$ http://www.cidades.ibge.gov.br/xtras/home.php>. Acesso em 11/02/2015.

LEPSCH, I. F. Formação e Conservação Dos Solos. São Paulo: Oficina de Textos, 2002.

OLIVEIRA, W. de. Os Impactos Socioambientais Motivados pela UHE Porto Primavera no Município de Araurilândia - MS. Tese UNESP Presidente Prudente - SP, 2004. 